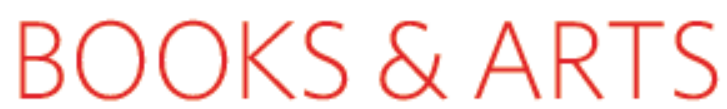

\title{
A change of mind?
}

\section{Putting evolutionary psychology to the test.}

Adapting Minds: Evolutionary Psychology

and the Persistent Quest for Human Nature by David J. Buller

Bradford Books: 2005. 552 pp.

$\$ 34.95, £ 22.95$

\section{Oliver Curry}

Evolutionary psychology argues that the human mind is a collection of special-purpose circuits designed by natural selection to solve the problems of survival and reproduction that were recurrent in the lives of our ancestors - problems such as finding food, picking habitats, attracting mates and navigating the social world.

In Adapting Minds, the philosopher David Buller aims to show that evolutionary psychology is "wrong in almost every detail". He argues that it is based on a mistaken view of neural development, that its reconstructions of the environment in which humans evolved are "pure guesswork", and that its major empirical findings are better explained by alternative theories. However, despite this barrage of criticism, Buller's attempted demolition ultimately fails.

First, Buller relies on the theory of 'neural darwinism' to argue that the functional organization of the brain is the product not of genetic instructions, but of a process analogous to natural selection that occurs during the lifetime of an individual. Buller claims that genes merely provide an initial over-supply of neurons and connections - a formless "mass of clay". These neurons then engage in a darwinian fight to the death, from which "circuits will develop that are specialized in dealing with whatever environmental inputs are most salient ${ }^{m}$. Thus the mind is not adapted to ancestral conditions; it is capable of adapting to whatever the immediate environment demands.

However, the notion that development resembles a darwinian struggle is spurious. To produce adaptations, natural selection requires numerous iterations of random variation and differential replication among competing entities. There is no equivalent process in development: neurons are not generated at random, 'successful' neurons are not reproduced, and the process is not repeated. As a result, there is no prospect of cumulative, adaptive evolution. Indeed, far from being in competition, from a genetic point of view,

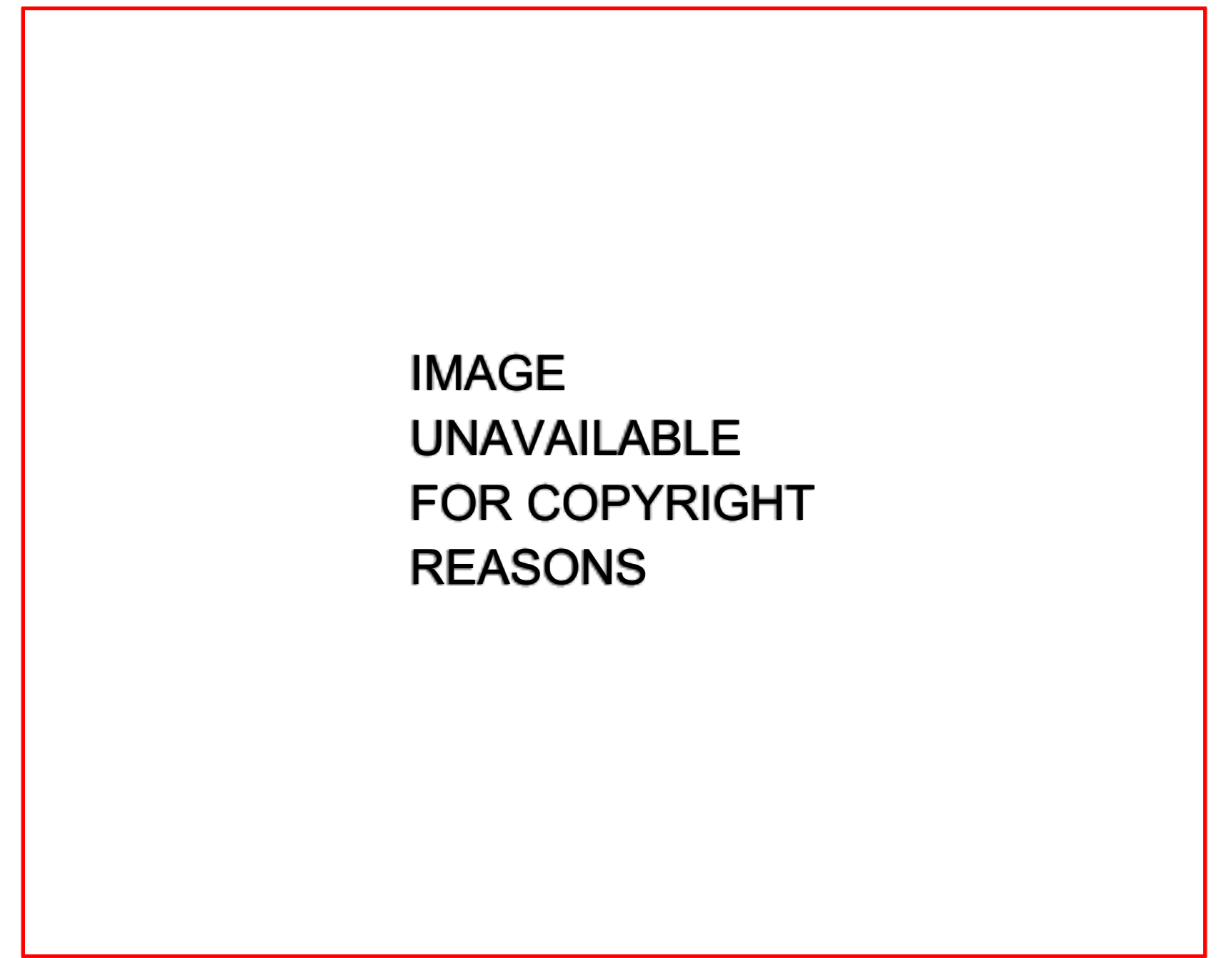

Looking for cues: infants have an innate ability to recognize faces and expressions.

neurons are on the same team. Development is better seen as the successful solution to a vast coordination problem involving an elaborate division oflabour.

The deeper problem with this account of development is that it supposes that neurons 'respond' to the environment in some general way. But, as Buller recognizes, such brains " would face the insoluble problem of learning which of the world's features are worth learning about before they set about learning about them. Later, Buller concedes that development must be guided by specific "innate hypotheses" about what to attend and respond to in the world. But the hypotheses that he proposes are woefully inadequate for the task. He suggests, for example, that the ability to recognize faces and facial expressions could begin in infants with nothing more than the hypothesis: "Triangulated high-contrast blobs are very important." This might direct the child to look in the right direction. But then what? Without further innate guidelines, development would stall for exactly the reason that Buller suggests. The development of each ability must be guided by its own rich battery of innate hypotheses. But with that, we arrive back at what evolutionary psychology had in mind all along.

So the question is not whether the brain exhibits innate structure, but of what that structure consists. This brings us to the second problem with Buller's analysis. He is fiercely critical of the methods that evolutionary psychologists use to investigate the selection pressures at work during human evolution. But he undermines these criticisms by using these same methods himself - and to good effect. For example, he argues that male sexual jealousy is a function of squandered "mating effort" rather than "uncertainty of paternity", and that much of the abuse of stepchildren is best viewed as a form of maternal infanticide. However, in doing so, Buller demonstrates despite his earlier scepticism - how the careful use of logic, game theory, comparative psychology, primatology and studies of huntergatherers can be used to construct plausible scenarios of ancestral conditions, and to generate testable predictions about human psychology and behaviour.

Finally, Buller's empirical criticisms tend to promise more than they deliver. He states, for example, that there is "no convincing evidence" 
that men have an evolved preference for mating with young women. But what he actually argues is that some men find young women attractive all the time, and that all men find young women attractive some of the time, but that not all men find young women attractive all of the time. This is perfectly consistent with the standard view from evolutionary psychology, in which a preference for youth is only one among many aspects of evolved male sexual psychology.

Adapting Minds is destined to become required reading among evolutionary psychology's detractors. But, despite its flaws, it will be read with interest by evolutionary psychologists too. Buller provides a useful overview of the field and of the current debates. He challenges evolutionary psychologists to reexamine which of their theoretical commitments are important and why. He advances alternative evolutionary hypotheses, which, far from replacing evolutionary psychology, could contribute to its ongoing refinement. And, above all, by eschewing the personal and political mudslinging that characterized earlier debates over sociobiology, Buller enables evolutionary psychologists to get back to arguing about the science.

Oliver Curry is in the Workshop in Political

Theory and Policy Analysis, Indiana University, 513 North Park, Bloomington, Indiana 474083895, USA.

\section{EXHIBITION}

\section{Engineering space-time}

\section{Albert Einstein: Ingenieur des Universums/Chief Engineer of the Universe \\ At Kronprinzenpalais, Ber lin until \\ 30 September 2005 \\ www.einsteinausstellung.de}

\section{Alison Abbott}

“Dr Albert Einstein, Chief Engineer of the Universe, School of Advanced Study, Princeton..." An envelope so addressed is one of more than a thousand items now on display at the Kronprinzenpalais in Berlin.

Did Einstein consider himself American? Or Swiss? Or German? What should we make of this Jew who first renounced German citizenship in 1896, when he was studying in Zurich, who fled from Berlin and the Nazis in
1933 , and whose reputation in his homeland was smeared by many in his own scientific community? Is it not perplexing that Germany has put on the world's most ambitious - and arguably the most impressive, thoughtful and imaginative - exhibition commemorating Einstein's life and scientific achievements, implicitly claiming him as their own?

The exhibition is challenging, and in a world used to dumbing down, it may be seen as an élite indulgence. Only visitors with some background in physics who are comfortable with abstract concepts will be rewarded, but they will find it extremely enriching. It presents Einstein and his science in many different contexts: his life and loves in politically turbulent times, for example, but most pertinently, the state of science when he began his working life.

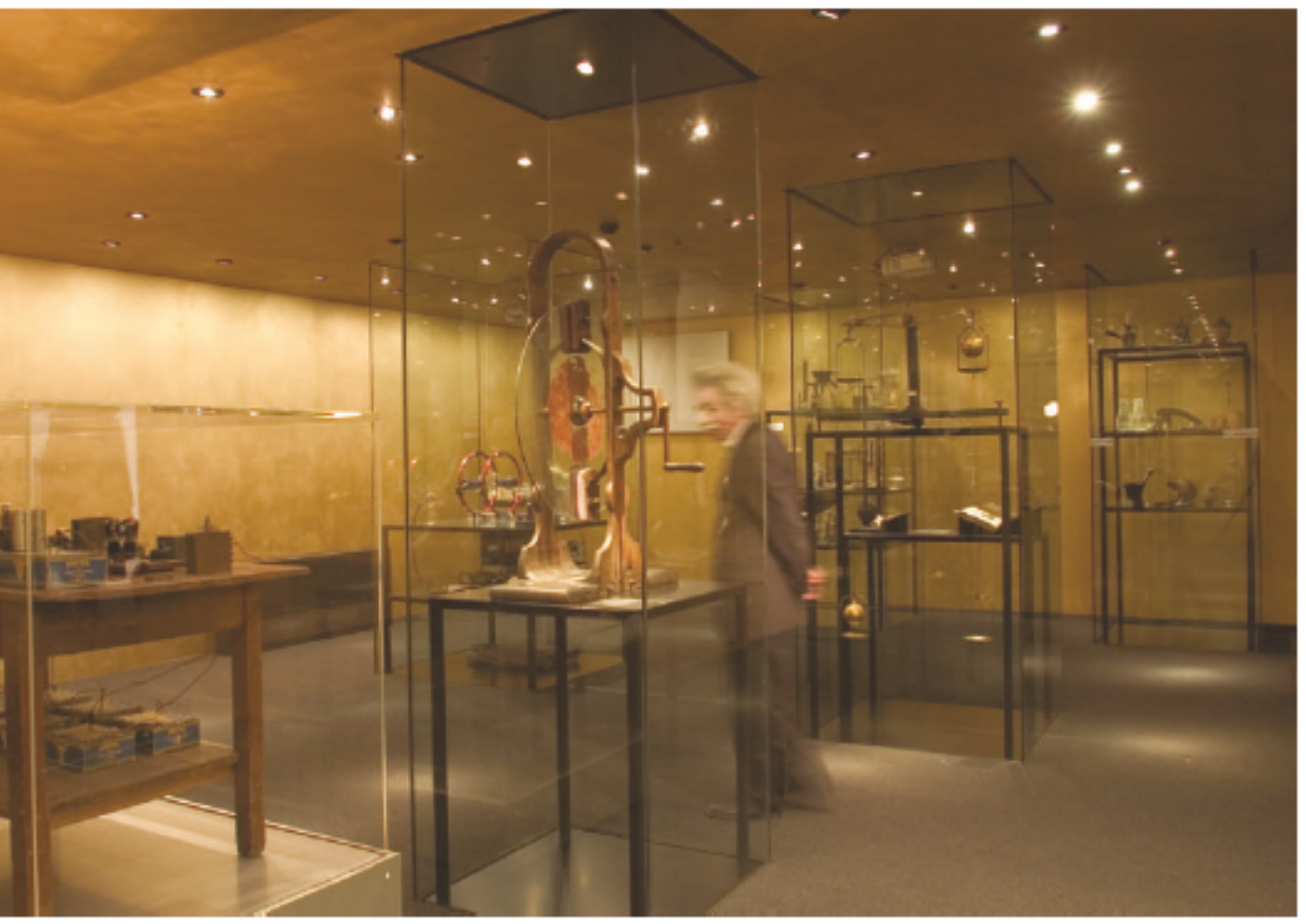

The ghost of Albert Einstein haunts the room of invisible forces at a Berlin exhibition in his honour.
The first of three exhibition floors in the old palace, converted at a cost of $€ 4$ million (US\$5 million), is dedicated to setting the scientific scene. A core concept is the history of the development of scientific ideas, elegantly demonstrated in two ground-floor rooms, one dedicated to invisible forces such as magnetism and electricity, the other to the Universe. The rooms display historic instruments, from Galileo's telescope to Otto Hahn's nuclear fission equipment, set among interactive computer terminals that access deeper levels of digital information, including films and sound recordings of some of the scientists. These rooms show how physics concepts developed, one discovery at a time, bringing the visitor to the point at which Einstein entered the fray.

The room near the entrance is empty, its space filled only with one of those impossible debates about which scientists like to fantasize. On three of its walls the projected figures of Aristotle, Newton and Einstein discuss gravity. The actors convey the scientists' personalities, as well as their understanding of the physical world. Introducing themselves, Einstein respectfully hails Aristotle as a true researcher, while Newton arrogantly sneers at Aristotle's "belief in fairy tales".

The second floor is dedicated to Einstein's life, childhood, family, politics, and the social and scientific realities of his world. A second impossible debate takes place, this time between Ludwig Boltzmann, Hendrik Lorentz and Max Planck, frustrated by the apparent dead-end that their physics had reached. The stroke of genius that shifted physics into higher gear - Einstein's special theory of relativity - is celebrated in the central room of the exhibition space. This is lit dazzlingly white and contains only a single central column, an elaborate interactive digital display that illustrates and explains the theory.

The third floor is dedicated to Einstein's legacy, the influence of his work on science and culture today. It is a jamboree of modern experimentation with direct connections to experiments at laboratories such as CERN and the European Southern Observatory.

Nearly halfway through this centenary of Einstein's annus mirabilis, and with Einsteinfatigue already setting in, it isstill worth spending hours, or even days, at this exhibition. It has an intellectual depth rarely attempted in exhibitions today, and is well served by its elegant presentation. But visitors will have to sweat for their pleasure. They will need the students ('explainers'), present in each room for the exhibition's five-month run, to help them find their way through the maze of information.

Poignantly, the exhibition opened a week after Berlin's Holocaust memorial opened to the public nearby. And many of the artefacts on display were provided by the Hebrew University of Jerusalem, which has a remarkable Einstein collection. Time provides perspective and equilibrium.

Those who pay the exhibition the attention 